\title{
Combining the reasoned action approach and habit formation to reduce sitting time in classrooms: Outcome and process evaluation of the Let's Move It teacher intervention
}

\author{
Katariina Köykkäa ${ }^{\mathrm{a}}$ Pilvikki Absetz ${ }^{\mathrm{b}}$, Vera Araújo-Soares ${ }^{\mathrm{c}}$, Keegan Knittle ${ }^{\mathrm{a}}$, Falko F. Sniehotta ${ }^{\mathrm{c}}$, \\ Nelli Hankonen ${ }^{\mathrm{a}, *}$ \\ a Social Psychology, Faculty of Social Sciences, University of Helsinki, Unioninkatu 37, 00014 Helsinki, Finland \\ ${ }^{\mathrm{b}}$ Department of Public Health and Clinical Nutrition, University of Eastern Finland (UEF), Kuopio Campus, P.O. Box 1627, 70211 Kuopio, Finland \\ ${ }^{\mathrm{c}}$ Institute of Health \& Society, School of Psychology, Faculty of Medical Sciences, Newcastle University, Baddiley-Clark Building Richardson Road, NE2 4AX Newcastle, UK
}

\section{A R T I C L E I N F O}

\section{Keywords:}

Theory-based intervention

Reasoned action approach

Habit formation

Behaviour change techniques

Fidelity

Sedentary behaviour

School-based health promotion

\begin{abstract}
A B S T R A C T
Creating active classroom environments and reducing excessive student sitting requires changes in teachers' behaviours. This study examines a teacher training intervention, which aimed to increase the extent to which teachers use strategies to interrupt prolonged periods of students' sitting, as well as strategies to reduce total sitting time. The training was part of the Let's Move It (LMI) multi-level school-based intervention that aimed to reduce sedentary behaviour and increase physical activity among older adolescents, drawing on insights from social psychological theories, such as the reasoned action approach, self-regulation approaches and habit formation. We explore (1) whether the intervention increased teachers' use of sitting reduction strategies, (2) whether theoretical mechanisms mediated these changes, and (3) how teachers utilized habit formation. This pragmatic experimental study of vocational school teachers $(n=234)$ was embedded within a cluster-randomized controlled trial evaluating LMI, in which schools were randomized to intervention or no-treatment control arms. Three intervention workshops targeted skills and motivation to use sitting reduction strategies in class (e.g., active teaching methods, activity breaks). Participants self-reported sitting reduction activities, theoretical mediators, and use of behaviour change techniques (BCTs) at baseline and 8-weeks follow-up. Compared to controls, intervention schools' teachers increased breaks to interrupt sitting, but not their outcome expectations, perceived behavioural control or intentions - potentially due to ceiling effects. Effects were mediated by BCT use and perceived behavioural control. Descriptive norms mediated the effects of the intervention on intention, which in turn mediated the intervention effects on BCT use. BCT use and intention were positively related to reducing students' sitting.
\end{abstract}

\section{Introduction}

\subsection{Importance of reducing sedentary behaviour in schools to improve} health

Sedentary behaviour, defined as sitting or reclining that results in little energy expenditure above rest (Owen, Sparling, Healy, Dunstan, \& Matthews, 2010), is common. Many everyday situations and settings implicitly or explicitly encourage sedentary behaviour: people spend substantial amount of time daily sitting in transportation, at work, at school, and in their leisure time. Among adults, excessive sedentary behaviour is associated with cardiovascular disease, type 2 diabetes and metabolic syndrome (Rezende, Rey-López, Matsudo, \& Luiz, 2014), and is a risk factor for mortality, independent of moderate-to-vigorous physical activity (Koster et al., 2012). Among children and adolescents age five to 17, excessive sedentary behaviour has been associated with unfavourable body composition (e.g. body mass index, waist circumference), decreased fitness, lowered self-esteem and pro-social behaviour, and decreased academic achievement (Carson et al., 2016). Adopting a non-sedentary lifestyle during childhood or adolescence may also have important preventive value later in life (Biddle, Pearson, Ross, \& Braithwaite, 2010; Thorp, Owen, Neuhaus, \& Dustan, 2011).

Schools are an ideal setting for interventions targeting behavioural changes among adolescents, as they reach majority of the target

\footnotetext{
* Corresponding author.

E-mail addresses: katariina.koykka@helsinki.fi (K. Köykkä), pilvikki.absetz@gmail.com (P. Absetz), vera.araujo-soares@newcastle.ac.uk (V. Araújo-Soares), keegan.knittle@helsinki.fi (K. Knittle), falko.sniehotta@newcastle.ac.uk (F.F. Sniehotta), nelli.hankonen@helsinki.fi (N. Hankonen).
} 
population that also spends a major part of their time in school. As school days also typically include long periods of uninterrupted sitting, schools have great potential to reduce adolescents' sedentary time. School-based interventions have largely focused on increasing students' moderate-to-vigorous physical activity, and less on engagement in light physical activity (i.e. not being sedentary) or introducing breaks to sedentary time (Morton, Atkin, Corder, Suhrcke, \& van Sluijs, 2016). There is currently little evidence of which strategies can effectively reduce sedentary behaviour at schools, especially among older adolescents (Hynynen et al., 2016; Morton et al., 2016), as most research in this area has focused on younger age groups.

\subsection{Teacher behaviour as a key to changing student health behaviours}

As teachers control the classroom environment and can shape students' activity behaviour in school, they are ideally placed to deliver interventions. When teachers implement interventions, the sustainability of these programs largely depends on teachers' willingness and ability to implement these in the long term (Lander, Eather, Morgan, Salmon, \& Barnett, 2017). However, the training of teachers within school-based physical activity interventions has remained both underreported and understudied (Lander et al., 2017).

Teachers' resources to implement behaviour change interventions are limited by work overload and competing demands related to curricular needs (Laine, Araújo-Soares, Haukkala, \& Hankonen, 2017; Naylor et al., 2015). Therefore, continuously implementing activities to reduce students' sitting time may require too much cognitive effort in the long term. Habit formation has been proposed as a possible means to aid maintenance of behaviour change beyond the intervention period, as habitual behaviours are performed frequently and automatically (Lally \& Gardner, 2013).

Habit is a process by which environmental cues automatically activate an impulse towards action that has, through repetition, become associated with those cues (Gardner, 2015). Habits develop through repetition of behaviour in a specific context, which reinforces a mental context-behaviour association, so that other options become less accessible in memory (Gardner, 2015). Habit formation has been suggested as a potential mechanism for sustained behaviour change as habits prompt frequent performance of a behaviour and may dominate over intentions in regulating behaviour (Gardner, 2015; Lally \& Gardner, 2013).

Purposeful habit formation usually involves choosing a target behaviour and defining its performance context (i.e., cue) (Gardner, Sheals, Wardle, \& McGowan, 2014). However, not all target behaviours and cues are equally suited to habit formation. Gardner et al.'s (2014) framework proposes five criteria for the quality of habit-formation goals, based on theoretical principles of behaviour change and habit formation (see Table 1). According to this framework, high-quality habit-formation goals should (1) specify a single target behaviour; (2) specify a frequency of the target behaviour; (3) specify the behaviour in absolute (not relative) terms; (4) relate to an increase in the target behaviour (as opposed to a decrease); and (5) identify salient, eventbased cues for performance. Because it is difficult to identify goal

Table 1

Suboptimal values for characteristics of habit formation plans analysed (Gardner et al., 2014).

\begin{tabular}{ll}
\hline Characteristic & Suboptimal value(s) \\
\hline Number of target behaviours specified & $\begin{array}{l}\text { More than one, no target } \\
\text { behaviour specified } \\
\text { Unspecified }\end{array}$ \\
$\begin{array}{l}\text { Target performance frequency } \\
\text { Target behaviour described in absolute or } \\
\text { relative terms }\end{array}$ & Relative terms \\
$\begin{array}{l}\text { Increase or decrease in target behaviour } \\
\text { Type of cue }\end{array}$ & $\begin{array}{l}\text { Decrease } \\
\text { Time-based cues }\end{array}$ \\
\hline
\end{tabular}

characteristics that are uniformly conducive to habit-formation across behaviours and contexts, the framework focuses on the values that are theoretically least conducive (suboptimal) to habit formation for each of the five characteristics (Gardner et al., 2014).

A conscious decision on what specific behaviour one wants to make habitual is a prerequisite for the formation of novel habits. Conscious processes can be addressed by social cognitive models such as the reasoned action approach (RAA) (Fishbein \& Ajzen, 2010). This theory postulates that intention is a key predictor of behaviour, and that intentions are a function of attitudes, perceived behavioural control and perceived norms (including descriptive norms, i.e., what other people are perceived to do). These, in turn, are based on beliefs regarding expected outcomes, control, and norms. Meta-analytical evidence shows that experimentally induced changes in attitudes, norms, and perceived behavioural control are related to medium-sized changes in intention, and small to medium-sized changes in behaviour, irrespective of features of the targeted behaviour (Sheeran et al., 2016). To our knowledge, reasoned action approach has not been studied as a predictor of using strategies to reduce other people's excessive sedentary behaviour.

Theories of behaviour change imply several potentially effective behaviour change techniques (BCTs) (Michie et al., 2013) such as prompting participants to self-monitor their behaviour and make action plans. Some BCTs do not require a high level of participant engagement (e.g. when health promoters provide information on health consequences to them), but others require active use by the participants (e.g., self-monitoring) in order to have effects on behaviour. Use or 'enactment' of the skills learned in an intervention are in fact one facet of intervention fidelity (Bellg et al., 2004). However, very few intervention studies so far have assessed enactment (JaKa et al., 2016). While an intervention may be delivered with high fidelity (by the provider), that does not necessarily mean that all or even most participants actually take up and enact the intended BCTs. Participants should both understand the skills taught to them, and enact them, otherwise the intervention may not have intended effects (Bellg et al., 2004). Therefore calls have been made to recognize BCT use as a key focus in process evaluation (Greaves, 2015). There are studies that have assessed use of self-regulatory BCTs (e.g. goal setting or action planning) after an intervention, e.g. (Hankonen, Absetz, Haukkala, \& Uutela, 2009; Knittle, De Gucht, Hurkmans, Vlieland, \& Maes, 2016), but rarely the whole range of BCTs that the participants are expected to use (see e.g. Bellg et al., 2004; Hankonen et al., 2015), including self-motivational BCTs that participants may use to enhance their motivation (Hankonen et al., 2017).

\subsection{The present study}

The teacher intervention evaluated in this study was embedded in a larger multi-component, multi-level intervention study called Let's Move It (LMI). LMI was a school-based intervention to promote physical activity and reduce sedentary behaviour among older adolescents, containing teacher-led activity breaks and other methods to reduce sedentary behaviour in classrooms (the focus of this study); efforts to increase environmental opportunities for physical activity (e.g., standing desks in classrooms); and six intra-curricular group sessions, online materials and a poster campaign for students. The teacher intervention aimed to increase teachers' efforts to reduce student sitting during class, by using strategies to interrupt prolonged periods of students' sitting, as well as strategies to reduce total sitting time.

In school-based health promotion, use of theory in intervention design has been associated with better outcomes (Peters, Kok, Ten Dam, Buijs, \& Paulussen, 2009). Theory is helpful in influencing the behaviour of intervention providers, such as teachers, as formal theories can guide the intervention development and inform formulation of intervention theory or logic model (Araújo-Soares, Hankonen, Presseau, Rodrigues, \& Sniehotta, in press). Therefore, theories and evidence of 
behaviour change informed the intervention development. Along with the entire Let's Move It intervention, also the teacher intervention component was based on insights from social psychological theories (e.g. the reasoned action approach, evidence-based strategies for habit formation) (Hankonen et al., 2016). The BCTs that the teachers were expected to take up were carefully mapped during intervention design that used both Intervention Mapping and Behaviour Change Wheel. The resulting intervention is described in Supplementary file, Table 1.

The value of testing complex theory-based interventions in the "real world", with field experiments, and evaluating them is increasingly being recognized. Evaluation should be conducted not only regarding the behavioural outcomes and effectiveness, but also regarding processes, as such evaluations provide important feedback to theory refinement (Moore et al., 2015). Indeed, a failure to produce effects may depend on several aspects that a thorough process evaluation can shed light on.

This study aims to address important gaps in previous research: Firstly, the reasoned action approach has never been studied in the context of sitting reduction behaviours, an emerging public health focus. Given the central role of teachers in prevention and health promotion in general, surprisingly little research has been conducted regarding teachers' role in school-based PA interventions, according to a recent systematic review (Lander et al., 2017). Secondly, the intervention did not rely on skills training only, but effectively aimed at using evidence and theory from behavioural science to improve rates of behaviour change. Indeed, the study first describes how a combination of social psychological theories and approaches that formed the basis of a teacher intervention, with specific behaviour change techniques - this content is carefully and transparently reported using the BCT Taxonomy (Michie et al., 2013). Finally, we experimentally investigate the corresponding assumed processes induced by an intervention tested in an experimental field design.

\subsection{Aims}

This study evaluates the outcomes and processes of the LMI teacher intervention. The central exploratory substantive hypotheses (derived from the intervention program theory) have been specified and registered in the Open Science Framework (osf.io/v94fw), along with the other assumptions of the program theory. This study will address the following questions:

1. Did the LMI teacher intervention increase teachers' use of sitting reduction strategies in the classroom?

2. Did the intervention change RAA constructs (outcome expectations, perceived behavioural control, descriptive norm, intention), and use of BCTs meant to increase use of sitting reduction strategies? While the study was not designed to test the effectiveness of the intervention, this paper explores if differences in primary and secondary outcomes are coherent with the logic model.

3. Are changes in teachers' use of sitting reduction strategies mediated by expected theoretical mechanisms? Specifically:

3.1. Do outcome expectations, perceived behavioural control and descriptive norms mediate the effect of the intervention on intention?

3.2. Did intention mediate the effect of intervention on BCT use?

3.3. Did intention, BCT use and perceived behavioural control mediate the effect of intervention on the two behaviours?

4. How were habit formation plans enacted by teachers? What were the interrelationships between habit formation plan enactment, automaticity and sitting reduction?

We also investigate how intervention session attendance was related to intervention effectiveness (i.e., changes in mediators and sitting reduction).

\section{Methods}

This study was conducted in the context of a cluster-randomized controlled trial evaluating the Let's Move It intervention. A full study protocol for the Let's Move It intervention (Hankonen et al., 2016) and the results of a feasibility study (Hankonen et al., 2017) have been published elsewhere. Another manuscript is in progress that will report results on the student participants in Let's Move It (their physical activity and sedentary behaviour, the primary outcomes of the trial at student level), but it will not report the outcomes among teachers. No other publications from the Let's Move It trial plan to make use of the teacher sample data reported here.

\subsection{Study design}

This is a pragmatic randomized sub-study with one intervention arm (Let's Move It workshops for teachers) compared with a control arm (no treatment). The school was the unit of cluster randomization to prevent contamination and for practical reasons. Schools were matched by the type of educational tracks they offered, so that the same educational tracks were allocated to both intervention and control arms. A statistician used a computerised random number generator to assign schools into control and intervention arms. It should be noted that while the main trial (Hankonen et al., 2016) had been powered to detect clinically meaningful and statistically significant differences in students, this sub-study concerns the teachers of these students, and was not designed to test the effectiveness of the teacher intervention on teacher behaviour. The method of determining the final sample size was based on the opportunistic pragmatic nature of this field trial. Data collection was not continued after data analysis. The substantive hypotheses of the teacher intervention's logic model have been registered to Open Science Framework (osf.io/v94fw). For the sake of space, not all of these hypotheses and measures are reported here but the ones determined in the aforementioned registration. Thus, all measures, manipulations, and exclusions in the study are disclosed and additional information is available from the main trial protocol (Hankonen et al., 2016) as well as from the authors. Study data will be made available in the Finnish Social Science Data Archive and via requests to the authors.

\subsection{Participants and eligibility criteria}

Six school units were recruited (three for intervention arm, three for control arm) in autumn 2014. Vocational schools had to agree to randomization and allow teachers to participate in the Let's Move It workshops during their working hours. Educational tracks chosen for the Let's Move It study were business and administration, information technology, nursing, and hotel, restaurant, and catering studies. Thus, the participants of this study are teachers of students from these educational tracks. For the teachers, inclusion criteria included being a core subject (e.g., mathematics, languages) or vocational subject (e.g. nursing) teacher who teaches at least one of the included classes in the study period and whose teaching involves a large amount of sitting and/or burdening work positions for students.

\subsection{Recruitment}

Before data collection, members of the research team gave a short presentation (5-10 min) to inform school staff of the purpose and background of the study, as well as data collection and intervention procedures. This meeting was used to recruit teachers to participate in the study. Teachers interested in participating were sent a link to an online questionnaire by e-mail. The first page of the online questionnaire included a link to the study information form, outlining the purpose and procedure of the study. Teachers were asked to indicate that they had read the information form, and provided informed consented to data collection, management and use detailed in the study 
information form by clicking "Yes," before they could move on to the actual questionnaire.

\subsection{Intervention}

Teachers from schools in the intervention arm received a training intervention to promote adoption and implementation of sitting reduction strategies in their classrooms. The objectives for the teacher intervention involved decreasing students' total sedentary time by introducing breaks in sedentary time, by using active teaching methods, and by providing options for light-intensity activity, such as gym balls to replace part of the classroom chairs and standing desks to replace part of the classroom tables (see full menu of options available in the sitting reduction strategy listing in the Supplementary file 2). As with the Let's Move It intervention as a whole (see Hankonen et al., 2016), the teacher intervention component was based on insights from social psychological theories, including the reasoned action approach, selfdetermination theory, self-regulation approaches and evidence-based habit formation strategies.

The intervention for teachers included three 90 -minute workshops ${ }^{1}$ delivered by the research staff, reminder emails, a manual and other materials (e.g., activity break posters). Workshops consisted of participatory tasks, discussion and small group work, and only brief sections of presentations by the facilitator. Each workshop had 2-10 participants and was led by one or two trained facilitators. Workshop and between-session email content is detailed in Supplementary file Table 1.

In workshop 1, the teachers first introduced themselves to each other and reflected on their personal motivation for reducing students' sedentary time in their lessons, using the Identifying Personal Motives Group Activity (Hankonen et al., 2017). The facilitator then gave a short presentation of the evidence regarding adverse effects of sedentary behaviour and the benefits of sitting reduction. Next, teachers discussed and tried out different sitting reduction strategies in small groups. At the end of the workshop, participants created a personal action plan for reducing student sitting in class for the next two weeks. Participants were also asked to monitor how well they followed the plan (i.e., plan enactment).

Participants were also given a 62-page manual demonstrating a range of strategies to reduce students' sitting. The manual additionally included exercises prompting the use of BCTs to support use of classroom sitting reduction strategies and tips for motivating students based on autonomy supportive communication. The classroom sitting reduction strategies (e.g. opinion poll queue, asking students to stand up when answering a question, an activity break with the help of an online video, starting each lesson by reminding the students that they are allowed to stand up during the lesson) that were promoted to teachers during the workshops and in the manual are presented in Supplementary file 2 .

Workshop 2 was organized two weeks after workshop 1. In workshop 2, teachers discussed their experiences of using classroom sitting reduction strategies as well as problems they had encountered, and brainstormed solutions to these problems in small groups. Next, teachers were also given a short presentation about habit formation, and instruction on how habit formation techniques can be employed to

\footnotetext{
${ }^{1}$ Workshop 3 was organized approximately six weeks after workshop 2 . In workshop 3, the teachers discussed their experiences of sitting reduction and habit formation. They also updated their habit formation plans. Again, they were asked to track their enactment of the habit formation plan for the next 3 weeks. The teachers also discussed how they could maintain sitting reduction practices after the active part of the intervention is over and created a calendar with monthly tips for sitting reduction. This part of the intervention was not included in the present short-term evaluation (Workshop 3 was organized after the 8-week follow-up data used in this study was collected) (see Hankonen et al. (2016)).
}

make use of sitting reduction strategies more automatic. They were then encouraged to create habit formation plans. By habit formation plan, we mean a specific type of action plan that includes the identification of cues and an aim of repeating consistently until the action becomes habitual and hence, automatic. The facilitator asked the teachers to independently choose 1) a sitting reduction strategy for which they would like to form a habit, and 2) a cue that could remind them about the use of this sitting reduction strategy. Teachers were asked to write down these habit formation plans in the form of "if (cue), then (sitting reduction strategy)", e.g. "If I need to give study materials to the students, then I ask them to come pick them up from my desk". Participants were asked to use the chosen sitting reduction strategy whenever they encountered the cue during the following three weeks and to track the enactment of their habit formation plan which specified the sitting reduction technique (i.e., behaviour, THEN part of plan) teachers intended to implement in response to a self-chosen contextual cue (i.e., IF-part of plan). Three weeks after the workshop they were sent an e-mail encouraging them to either continue with the habit formation plan they formed in the workshop or to create a new one. The program content had been developed in collaboration with representatives of the teachers, and the acceptability and feasibility of the proposed intervention components and research procedures was assessed in a feasibility study (Hankonen et al., 2017) before the definitive RCT. Teachers participating in the feasibility study reported high satisfaction with the workshops, indicating high acceptability. Both the students and the teachers reported a significant increase in teachers' use of classroom sitting reduction strategies after the intervention. Intervention components and research procedures for the RCT were refined based on the findings of the feasibility study. Teachers in the RCT had not been involved in the design of the intervention. Please note that not all elements of the teacher intervention are examined here (e.g. organizational level interventions on management and school principal who in turn also have had an influence on the teachers' behaviour, and workshop 3 which was arranged as a booster intervention later).

\subsection{Data collection}

Data was collected in 2015-2016 in six batches. Data was collected in parallel from teachers of the same educational tracks in both intervention and control arms (Hankonen et al., 2016). Link to the baseline questionnaire was sent to the teachers approximately one week before the first workshop for intervention arm teachers. Intervention arm teachers were asked to answer the questionnaire before attending the workshop. Link to the follow-up questionnaire was also sent to the teachers via e-mail eight weeks after baseline. Two reminder e-mails about answering the questionnaires were sent.

\subsection{Measures}

Participants' socio-demographic and other relevant background information (year of birth, education, subjects they teach, and type of classroom usually used) was collected at baseline.

Also, a set of social and psychological constructs related to reducing students' sitting, as well as sitting reduction behaviour was measured. To make sure all respondents have a similar understanding of classroom sitting reduction, the following definition was provided in the questionnaire: "In this questionnaire, students' sitting reduction means that during their lessons the teacher enables students to decrease their total sitting time and take breaks from sitting at least once every $30 \mathrm{~min}$ so that the students stand up from their chairs".

Activities to reduce students' sedentary time were measured with two items formulated to reflect the two goals of the intervention. Item stem was "Please estimate how often you have used the following means to reduce students' sitting in your lectures (à 45 minutes) during the last two weeks" and the items were "I reduced students' total sitting time during lessons" (i.e., use of strategies to reduce total sitting time) 
and "I introduced breaks to students' sitting during lessons" (i.e., use of strategies to introduce breaks to sitting). The response alternatives were "Never" (1), "Once" (2), "A few times" (3), "On about every fourth lecture" (4), "On about every second lecture" (5), "On most lectures" (6) and "On every lecture" (7).

The social cognitive variables were designed using widely accepted methods (Francis et al., 2004). Intention was measured with two items. The item was "I intend to reduce students' sitting during my lessons in the future" and it was answered on two scales: 1 (unlikely) to 7 (likely) and 1 (absolutely not) to 7 (absolutely yes). Outcome expectations were measured with 10 items based on teachers' focus group interviews (Laine et al., 2017). Item stem was "If I reduced students' sitting during my lessons, as a result...", and the items included e.g. "my lessons would be less peaceful", "students' ability to learn would be enhanced" and "students would be able to concentrate longer". Response alternatives ranged from 1 (completely disagree) to 7 (completely agree). Descriptive norm and injunctive norm were both measured with one item ("Most teachers use sitting reductions strategies during their lessons" and "School management would like me to use sitting reduction strategies during my lessons") on a 1 (completely disagree) to 7 (completely agree) scale (Francis et al., 2004). Perceived behavioural control with two items ("Whether I reduce students' sitting or not is entirely up to me" and "I am certain I can overcome obstacles that hinder reducing students sitting") (Francis et al., 2004). Response alternatives ranged from 1 (completely disagree) to 7 (completely agree). It should be noted that some publications refer to this construct as self-efficacy, and there is an overlap between both constructs - our measure captures both.

Behaviour Change Technique (BCT) use was measured with a selfreport scale adapted from previous studies (Hankonen et al., 2015, 2017). Items included both BCTs that individuals may use to maintain optimal motivation (e.g. "I have thought about why reducing students' sitting is important to me") and self-regulatory BCTs (e.g. "I have set myself a goal for reducing students' sitting") (Goal setting). Response alternatives ranged from 1 (not at all true) to 7 (completely true).

Automaticity of reducing students' sitting was measured with the four-item Self-Report Behavioural Automaticity Index (SRBAI, Gardner, Abraham, Lally, \& de Bruijn, 2012). Item stem was "Reducing students' sitting during my lessons is something that..." and items were e.g. "I do automatically" and "I do without having to consciously remind myself of". The items were rated on a 1 (completely disagree) to 7 (completely agree) scale.

Habit formation plan enactment was measured in the follow-up questionnaire by one item: "During the last month, how often have you done the following? I have repeated the same habit formation plan during my lessons". The response alternatives were "Never" (1), "Once" (2), "A few times" (3), "On about every fourth lecture" (4), "On about every second lecture" (5), "On most lectures" (6) and "On every lecture" (7). At follow-up, the participants were also asked to describe the habit formation plans they had used with open-ended questions (teachers could report up to three plans in the questionnaire). Whereas BCT use measured the uptake of various behaviour change techniques, including extent to which teachers had created a habit formation plan in the first place, 'habit formation plan enactment' assessed the extent to which these plans had been enacted in the intended situation, repeatedly, to create automaticity, the target psychological construct (as measured by the SRBAI).

\subsection{Analyses}

Patterns of missing data were analysed within the study variables, and found to be missing completely at random ( $p=.192$ for Little's MCAR test). Subsequently, missing data were imputed using multiple imputation techniques in SPSS (IBM Corporation, 2012), with values imputed based on regression models including all relevant demographic and theoretical variables at baseline and post-treatment. Descriptive statistics and correlations between study variables were then examined.
Mixed between-within subjects ANOVAs were conducted to assess changes in activities to reduce students' sedentary time, outcome expectations, norms, perceived behavioural control, intention and sitting deduction automaticity. Study allocation (intervention vs control group) was used as a between-subjects factor and time (baseline (T1) or 8-week follow-up (T2)) as a within-subjects factors. Partial eta squared effect sizes are reported for these ANOVAs, and Cohen's $d$ values are reported for between-groups comparisons of post-treatment values of outcome variables.

Mediation analyses were used to examine the extents to which changes in theoretical variables predicted teachers' intention, BCT use and use of sitting reduction techniques. In the first model, group allocation was entered as an independent variable, outcome expectations, descriptive norm and perceived behavioural control at T2 were entered as potential mediators, and intention as a dependent variable. In model two, group allocation was entered as an independent variable, intention at T2 as a potential mediator, and BCT use as a dependent variable. In model 3, group allocation was entered as an independent variable, intention, BCT use and perceived behavioural control at T2 were entered as potential mediators, and activities to reduce students' total sitting time as a dependent variable. Model 4 was similar to model three, except that activities to introduce breaks to students' sitting were entered as a dependent variable. All mediation analyses were conducted with the PROCESS macro for SPSS (Hayes, 2013) using 20,000 bootstrap resamples.

Teachers' habit formation plan enactment was examined with descriptive statistics. The habit formation plans reported by participants were content analysed following the framework of Gardner et al. (2014) to determine their appropriateness for habit formation. Each habit formation plan was rated by the first author on each of the five characteristics (Table 1) as either optimal or suboptimal, and frequencies of optimal and suboptimal values on each of the five characteristics were calculated.

\section{Results}

\subsection{Participant flow}

After schools were randomized to either the intervention arm or control arm, teachers from these schools were assessed for eligibility. Of those approached for participation, 117 were in the intervention arm schools and 116 were in the control arm schools. Of these, 77 and 46 teachers from the intervention and control arms, respectively, completed baseline measures and were enrolled in the study. In the intervention arm, 63 teachers received the intervention, meaning that they attended at least one workshop (59 attended workshop I and 50 attended workshop II). Between baseline and follow-up, 52 participants were lost to follow up (29 in the intervention arm and 23 in the control arm). Participant flow is presented in Fig. 1. Drop-out analyses indicated that teachers who only responded at baseline $(n=52)$ reported reducing students' sedentary time significantly more frequently and presented higher sitting reduction automaticity levels at baseline compared to those who responded at both time points $(n=71)$.

\subsection{Descriptive statistics}

Table 2 shows basic descriptive statistics. Most participants were women who taught vocational subjects. Most participants taught in sedentary classrooms with tables and chairs, and very few in vocational classrooms.

Bivariate correlations (Table 3) indicate that both behavioural outcomes (introducing activity breaks and using other strategies to reduce sitting) were strongly and significantly correlated with each other at $\mathrm{T} 1(r=0.69)$ and $\mathrm{T} 2(r=0.72)$. The interrelationships between other variables under study were also correlated in a manner consistent with theoretical expectations. Attendance to intervention 


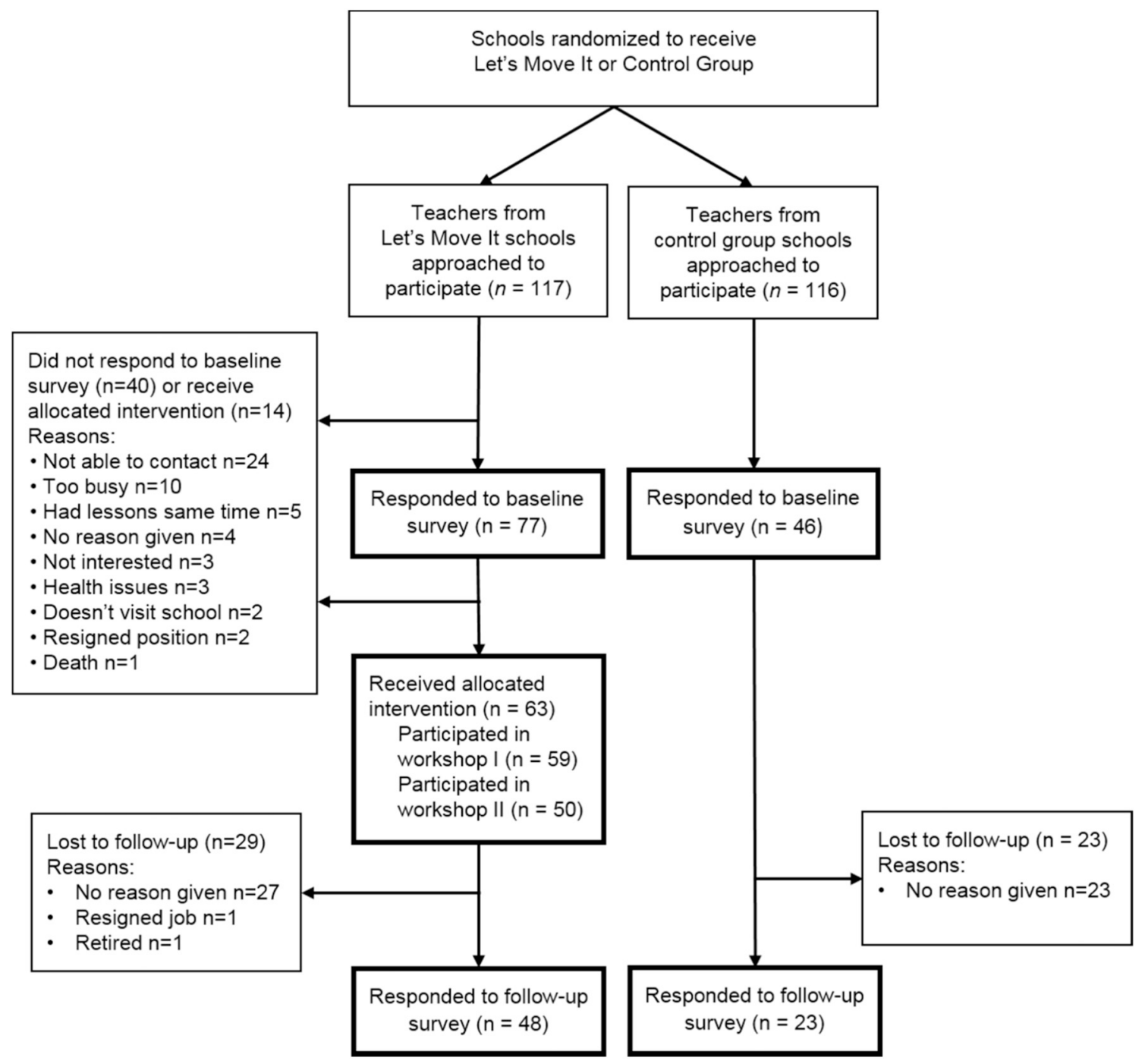

Fig. 1. CONSORT flow diagram of teacher participants within the Let's Move It trial.

Table 2

Descriptive statistics.

\begin{tabular}{|c|c|c|}
\hline Characteristic & Intervention $(n=77)$ & $\begin{array}{l}\text { Control } \\
(n=46)\end{array}$ \\
\hline Age, M (SD) & $46.4(10.0)$ & $48.5(9.7)$ \\
\hline \multicolumn{3}{|l|}{ Gender } \\
\hline Male, n (\%) & $15(19.5 \%)$ & $11(23.9 \%)$ \\
\hline Female, n (\%) & $61(79.2 \%)$ & $34(73.9 \%)$ \\
\hline Missing n (\%) & $1(1.3 \%)$ & $1(2.2 \%)$ \\
\hline \multicolumn{3}{|l|}{ Subjects taught } \\
\hline Vocational subjects, n (\%) & $45(58.4 \%)$ & $29(63.0 \%)$ \\
\hline $\begin{array}{l}\text { Health education or physical } \\
\text { education, } \mathrm{n}(\%)\end{array}$ & $2(2.6 \%)$ & $2(4.3 \%)$ \\
\hline General subjects, n (\%) & $30(39.0 \%)$ & $15(32.6 \%)$ \\
\hline \multicolumn{3}{|l|}{ Type of classroom usually used } \\
\hline $\begin{array}{l}\text { Classroom with tables and chairs, } \mathrm{n} \\
(\%)\end{array}$ & $61(70.2 \%)$ & $33(71.7 \%)$ \\
\hline $\begin{array}{l}\text { Vocational classrooms where } \\
\text { students mostly stand, n (\%) }\end{array}$ & $8(10.4 \%)$ & $7(15.2 \%)$ \\
\hline $\begin{array}{l}\text { Vocational classrooms where } \\
\text { students mostly sit, n (\%) }\end{array}$ & $8(10.4 \%)$ & $6(13.0 \%)$ \\
\hline
\end{tabular}

sessions was not clearly associated with the primary outcome of using sitting reduction strategies at T2. There were positive but weak associations between session attendance and positive outcome expectations, intention, and use of BCTs to change one's own behaviour (see Table 3).

\subsection{Intervention effects on primary and secondary outcomes}

There were significant group $\times$ time interactions for activities to introduce breaks to students' sitting time $(\mathrm{F}(1,110)=2.17, p=.001$, partial $\eta 2=0.10$ ), which translates to a medium effect of the intervention at post-intervention. There were no significant group $\times$ time interactions for other activities to reduce students' total sitting time ( $\mathrm{F}$ $(1,110)=1.55, p=.215$, partial $\eta 2=0.01)$, outcome expectations $(\mathrm{F}$ $(1,110)=2.27, p=.135$, partial $\eta 2=0.02)$, perceived behavioural control $(\mathrm{F}(1,110)=2.26, p=.136$, partial $\eta 2=0.02)$ or automaticity $(\mathrm{F}(1,110)=88, p=.349$, partial $\eta 2=0.01)$. There was also a significant group $\mathrm{x}$ time interaction for intention to reduce students' sitting $(\mathrm{F}(1,110)=6.84, p=.010$, partial $\eta 2=0.06)$, but this effect was in the opposite direction to our hypotheses. Means, standard deviations and effect sizes for these analyses are presented in Table 4. Automaticity and perceived behavioural control demonstrated increasing trends over time in both arms.

Table 5 shows $t$-tests for the variables that were only measured at follow-up. Descriptive norms were significantly higher in the intervention arm teachers, as was self-reported use of BCTs to change own behaviour is higher among intervention arm, as expected. These differences are in the small range of effect sizes. There were only minimal differences between groups in injunctive norms and use of frequencyrelated BCTs. 


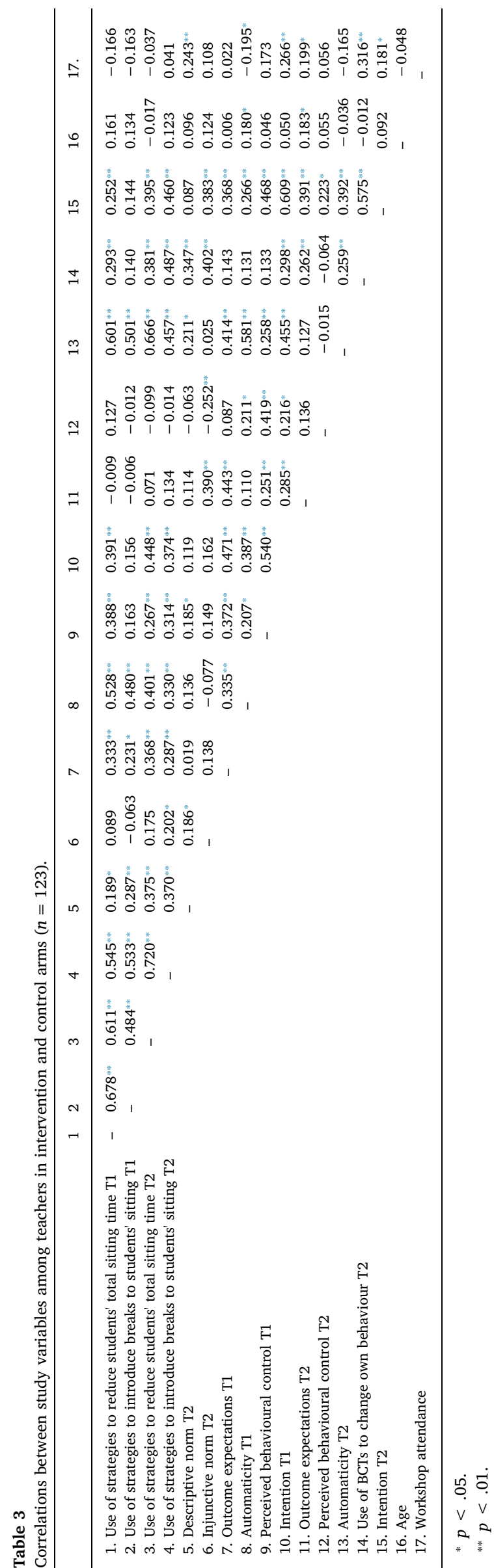

\subsection{Mediation of intervention effects}

Table 6 presents data for the four models examining the patterns outlined by the logic model. Model 1 shows that the intervention was associated with higher descriptive norms at $\mathrm{T} 2$, but not perceived behavioural control or outcome expectations. All three mediator variables significantly predicted intentions. The relationship between the intervention and intentions was only mediated by descriptive norms. Model 2 indicates that although the intervention did not induce higher intentions, there was evidence for a significant indirect effect of the intervention on BCT use via intention. This indirect effect was driven in a large part by the strong relationship between intention and BCT use.

Models 3 and 4 investigated the extents to which BCT use, perceived behavioural control and intention mediated the effects of the intervention on the main outcome variables of the study (strategies to reduce total sitting time in Model 3, and introducing sitting breaks in Model 4). In both Model 3 and Model 4, the intervention was related to higher levels of BCT use, and all mediator variables (BCT use, perceived behavioural control and intention) were significantly related to the two sitting reduction behaviours. Model 3 did not reveal any significant indirect effects, whereas Model 4 revealed a significant indirect effect of the intervention on strategies to introduce breaks to sitting via BCT use.

\subsection{Habit formation}

At T2, 37.8\% $(n=17)$ of the intervention arm respondents reported not enacting habit formation plans at all during the last month. Habit formation plans were enacted regularly (on about every fourth lecture or more often) by $15.5 \%(n=7)$ of the respondents.

At T2, frequency of habit formation plan enactment was not related to sitting reduction automaticity among intervention arm teachers $\left(r_{s}=0.05, p=.759\right)$. However, within the whole dataset there was a positive correlation between automaticity and actions to reduce students' total sitting time $\left(r_{s}=0.44, p<.001\right)$ as well as automaticity and introducing breaks to students' sedentary time $\left(r_{\mathrm{s}}=0.29\right.$, $p<.001$ ) at $\mathrm{T} 2$.

Twenty of the 45 intervention arm teachers who had completed T2 measures and who had attended at least one workshop reported at least one habit formation plan that they had created. Seven participants reported one, 6 participants reported two and 6 participants reported three habit formation plans. Thus, altogether 37 habit formation plans were content analysed. The three most common examples of habit formation plans reported by teachers were "If I have study materials for the students, I ask them to come pick them up from my table", "If students are restless, we hold an activity break", and "In the beginning of a lesson I remind the students of the possibility to use PA equipment".

The results of the content analysis of the habit formation plans are presented in Table 7. Most habit formation plans (92.5\%) included only one behaviour, as had been advised. The types of cues reported were also mostly optimal for habit formation. However, frequency of target behaviour was suboptimal (unclear or unspecified) in $80 \%$ of the habit formation plans reported.

\section{Discussion}

This study set out to conduct an exploratory outcome and process evaluation of the Let's Move It intervention's teacher training intervention, focusing on the mechanisms postulated by the reasoned action approach and habit formation. Both behaviours changed to the expected direction although a statistically significant effect only emerged in breaking sitting. Descriptive norm as well as use of BCTs to change own behaviour was higher among intervention arm teachers at T2. A set of mediation analyses showed that the intervention influenced descriptive norm, which in turn increased intention, which via BCT use led to use of more sitting reduction strategies. Intention was moderately 
Table 4

Intervention effects on changes in primary and secondary outcomes.

\begin{tabular}{|c|c|c|c|c|c|}
\hline & Intervention arm $\mathrm{M}(\mathrm{SD})$ & Control arm M (SD) & $\mathrm{d}(95 \% \mathrm{CI})^{\mathrm{a}}$ & $\mathrm{p}$-Value ${ }^{\mathrm{b}}$ & Effect size \\
\hline Activities to reduce students' total sitting time & & & & .215 & 0.014 \\
\hline Baseline & $3.16(1.71)$ & $3.33(1.87)$ & & & \\
\hline Follow-up & $3.88(1.64)$ & $3.62(1.98)$ & $0.15(-0.22,0.51)$ & & \\
\hline Activities to introduce breaks to students' sitting time & & & & .001 & 0.097 \\
\hline Baseline & $3.30(1.99)$ & $3.62(2.41)$ & & & \\
\hline Follow-up & $4.28(1.96)$ & $3.23(2.19)$ & $0.51(0.14,0.88)$ & & \\
\hline Outcome expectations & & & & .135 & 0.020 \\
\hline Baseline & $5.47(0.87)$ & $5.39(1.09)$ & & & \\
\hline Follow-up & $5.34(0.97)$ & $4.98(1.27)$ & $0.33(-0.04,0.70)$ & & \\
\hline Perceived behavioural control & & & & .136 & 0.020 \\
\hline Baseline & $5.19(1.26)$ & $4.83(1.57)$ & & & \\
\hline Follow-up & $5.26(1.41)$ & $5.30(1.38)$ & $-0.03(-0.39,0.34)$ & & \\
\hline Intention & & & & .010 & 0.059 \\
\hline Baseline & $5.63(1.11)$ & $4.83(1.64)$ & & & \\
\hline Follow-up & $4.97(1.64)$ & $4.84(1.79)$ & $0.08(-0.29,0.44)$ & & \\
\hline Automaticity & & & & .349 & 0.008 \\
\hline Baseline & $3.14(1.61)$ & $3.59(2.04)$ & & & \\
\hline Follow-up & $3.87(1.79)$ & $4.03(2.24)$ & $-0.08(-0.45,0.28)$ & & \\
\hline
\end{tabular}

a Cohens $d$ based on between-groups comparison of follow-up measurements.

b Main effects of group $\times$ time interaction based on repeated measures mixed ANOVAs.

Table 5

Intervention effects on secondary outcomes only measured at follow-up.

\begin{tabular}{|c|c|c|c|c|c|}
\hline & $\begin{array}{l}\text { Intervention } \\
\text { arm M (SD) }\end{array}$ & $\begin{array}{l}\text { Control } \\
\text { arm M } \\
\text { (SD) }\end{array}$ & $\begin{array}{l}95 \% \mathrm{CI} \text { for } \\
\text { mean } \\
\text { difference }\end{array}$ & $\mathrm{t}$ & df \\
\hline Descriptive norm & $3.65(1.98)$ & $\begin{array}{l}2.97 \\
(1.55)\end{array}$ & $0.21,1.15$ & $1.87^{* * *}$ & 121 \\
\hline Injunctive norm & $4.20(1.67)$ & $\begin{array}{l}3.83 \\
(1.88)\end{array}$ & $-0.27,1.02$ & 1.15 & 121 \\
\hline $\begin{array}{l}\text { Use of BCTs to } \\
\text { change own } \\
\text { behaviour }\end{array}$ & $4.11(1.71)$ & $\begin{array}{l}3.36 \\
(1.68)\end{array}$ & $0.12,1.38$ & $2.37^{*}$ & 121 \\
\hline
\end{tabular}

related to higher use of BCTs. Sitting reduction automaticity increased in both arms. BCT use explained the effect of intervention on introducing breaks to sitting. Only a minority utilized habit formation. Content analysis showed that the intervention arm teachers mostly wrote their habit formation plans in line with the given criteria, the most prevalent problem being the unspecified frequency of the response in their plans.

On the whole, most of the changes in this pragmatic sub-study embedded in a larger field experiment did not show statistical significance, which would be expected due to the small sample size resulting from an opportunistic pragmatic design. Therefore, the focus in interpreting the results should be on the effects and confidence intervals. In the intervention arm, 63 teachers participated in the workshops. For most variables, the effect sizes were small, with changes in the expected directions, except for the finding that intervention arm teachers' intention decreased. This may be partly explained by a particularly high baseline value, which perhaps is explained by participants' knowledge of intervention arm allocation and social desirability effect, thus leading to a ceiling effect and regression to the mean. It is notable that the control arm's intention absolute value is at both times lower than that of the intervention arm. A speculative explanation could be that the intervention arm teachers are fatigued and discouraged during the intervention and that the decrease is not only due to a statistical artefact. However, the intentions never go below those of the control arm teachers, so the latter explanation is unlikely.

Perceived behavioural control, descriptive norm and outcome expectations were associated with intention in line with the reasoned action approach and empirical research in other behavioural domains (McEachan et al., 2016). After the intensive intervention, intervention arm teachers experienced reasonably higher levels of descriptive norm than did control arm teachers, however no differences in injunctive norms (from school management) were found, although the effect is

Table 6

Mediation analyses.

\begin{tabular}{|c|c|c|c|c|c|c|}
\hline \multirow[t]{2}{*}{ Model } & \multicolumn{2}{|l|}{ a paths } & \multicolumn{4}{|l|}{ b paths } \\
\hline & Condition $^{\mathrm{a}} \rightarrow \mathrm{MV}$ & Mediator variable (MV) & $\mathrm{MV} \rightarrow \mathrm{DV}$ & Dependent variable (DV) & $\begin{array}{l}\mathrm{a} \times \mathrm{b} \text { paths } \\
\text { Indirect effect }\end{array}$ & $95 \%$ confidence interval of $a \times b$ \\
\hline \multirow[t]{3}{*}{1} & -0.24 & $\mathrm{~T} 2$ outcome expectations & $0.52^{* *}$ & \multirow[t]{3}{*}{ T2 Intention } & -0.13 & {$[-0.43,0.07]$} \\
\hline & $-0.68^{* * *}$ & $\mathrm{~T} 2$ descriptive norm & $0.24 *$ & & -0.16 & {$[-0.42,-0.02]$} \\
\hline & 0.08 & $\mathrm{~T} 2$ perceived behavioural control & $0.44^{* *}$ & & 0.04 & {$[-0.18,0.30]$} \\
\hline 2 & -0.06 & T2 intention & $0.71^{* *}$ & T2 BCT use & -0.71 & {$[-1.16,-0.26]$} \\
\hline \multirow[t]{3}{*}{3} & -0.06 & $\mathrm{~T} 2$ intention & $0.41^{* *}$ & \multirow[t]{3}{*}{ Use of strategies to reduce total sitting time } & -0.27 & {$[-0.70,0.11]$} \\
\hline & $-0.75^{*}$ & T2 BCT use & $0.29 *$ & & -0.02 & {$[-0.34,0.22]$} \\
\hline & 0.08 & $\mathrm{~T} 2$ perceived behavioural control & $-0.34^{* *}$ & & -0.22 & {$[-0.56,-0.04]$} \\
\hline \multirow[t]{3}{*}{4} & -0.06 & $\mathrm{~T} 2$ intention & $0.44 * *$ & \multirow[t]{3}{*}{ Use of strategies to introduce breaks to sitting } & -0.027 & {$[-0.77,0.26]$} \\
\hline & $-0.75^{*}$ & T2 BCT use & 0.32 & & -0.24 & {$[-0.68,-0.02]$} \\
\hline & 0.08 & $\mathrm{~T} 2$ perceived behavioural control & $-0.35^{*}$ & & -0.03 & {$[-0.26,0.14]$} \\
\hline
\end{tabular}

Model $1 \mathrm{R}^{2}=0.38, p<.0001$; Model $2 \mathrm{R}^{2}=0.51, p<.0001$; Model $3 \mathrm{R}^{2}=0.53, p<.0001$; Model $4 \mathrm{R}^{2}=0.30, p<.0001$.

a $1=$ intervention arm, $2=$ control arm.

$* p<.05$.

** $p<.01$ 
Table 7

Characteristics of habit formation plans based on content analysis.

\begin{tabular}{|c|c|c|c|}
\hline Characteristics & $\begin{array}{l}\text { Observed values }(*=\text { prejudged to be } \\
\text { suboptimal) }\end{array}$ & Verbatim examples & Observed frequency $(n=40)$ \\
\hline \multirow[t]{3}{*}{ 1. Number of target behaviours } & a. One behaviour & $\begin{array}{l}\text { “...I ask students to come pick material up from } \\
\text { my table" }\end{array}$ & $37(92.5 \%)$ \\
\hline & b. Two behaviours* & $\begin{array}{l}\text { "Something active, like blowing balloons, } \\
\text { clapping" }\end{array}$ & $1(2.5 \%)$ \\
\hline & a. No behaviour specified* & "When someone yawns or something like that" & $2(5 \%)$ \\
\hline \multirow[t]{2}{*}{ 2. Frequency of target behaviour } & a. During each lecture & "At the beginning of a lecture..." & $8(20 \%)$ \\
\hline & b. Unclear or unspecified* & "Tiredness - squats" & $32(80 \%)$ \\
\hline \multirow{3}{*}{$\begin{array}{l}\text { 3. Behaviour specified in absolute or relative } \\
\text { terms }\end{array}$} & a. Absolute & "...I show the students an activity break video" & $30(75 \%)$ \\
\hline & b. Unclear* & "....do something active together" & $8(20 \%)$ \\
\hline & c. No behaviour specified* & "When someone yawns or something like that" & $2(5 \%)$ \\
\hline \multirow[t]{3}{*}{ 4. Increase or decrease in target behaviour } & a. Increase in healthy behaviour & "Standing during presentations" & $37(92.5 \%)$ \\
\hline & b. Decrease in unhealthy behaviour* & "I won't bring materials for the students" & $1(2.5 \%)$ \\
\hline & c. No behaviour specified* & "An alarm after 25 min" & $2(5 \%)$ \\
\hline \multirow[t]{3}{*}{ 5. Type of cue } & a. Event-based & "At the beginning of a lecture" & $34(85 \%)$ \\
\hline & b. Time-based* & "After $2-3 \mathrm{~h} "$ & $4(10 \%)$ \\
\hline & c. No cue specified* & "Written exercise using the blackboard" & $2(5 \%)$ \\
\hline
\end{tabular}

almost of equal size as in the descriptive norm. One of the core theories of the entire Let's Move It intervention was the self-determination theory (Hankonen et al., 2016), whereby the intervention attempted to minimize social pressure, due to its possible adverse effects on controlled motivation or amotivation, thus also the intervention program theory did not hypothesize construct of injunctive norm to be an optimal mediator. Compared to previous experimental studies (Sheeran et al., 2016), the findings did not indicate effects of perceived behavioural control or outcome expectations on behaviour, which on the other hand may depend on ceiling effects (the means of these variables were very high already at baseline). Similarly to other studies, descriptive norms and intentions were found to play a key role.

Even strong intentions are not sufficient to change behaviour alone (Sheeran et al., 2016), therefore intervention logic model incorporated volitional, self-regulation techniques, including a habit formation component. The results show however that only a minority of participants consistently performed their planned sitting reduction strategy when encountering the cue, indicating problems in the acceptability of this component. However, also other studies have reported low levels of habit formation enactment. In one study, (Lally, van Jaarsveld, Potts, \& Wardle, 2010), even though participants had themselves chosen and defined the healthy eating, drinking or exercise behaviour they wanted to make habitual, and thus were motivated to create a habit, approximately half of them did not repeat the behaviour consistently enough to achieve habit status. Recent studies indicate that people prefer to plan physical activity, balance and strength exercises around time-based and event-based cues (Fleig et al., 2017, 2016). While specificity of cues and instrumentality of plans were important, they also found that- contrary to Gardner et al. (2014) - specificity of responses would not be necessary. In addition to habit formation, the findings indicate that the intervention was successful in increasing the use of BCTs to aid in behaviour change: In other similar studies, the uptake of BCTs has been less than optimal (e.g. Hankonen et al., 2015). Also, this study demonstrates small effects between the arms.

Most of the other school-based sitting reduction intervention studies have been carried out with younger age groups, the teachers of whom are faced with essentially different audience and tasks than teachers of older adolescents. Thus, direct comparison with other similar literature is challenging. A systematic review of school-based interventions targeting physical activity and sedentary behaviour among older adolescents identified only four interventions that explicitly targeted and measured sedentary behaviour (Hynynen et al., 2016). Even though these interventions were school-based, none of them specifically targeted sedentary behaviour during schooldays, but rather focused on students' overall or leisure time sedentary behaviour. Intervention strategies included physical education class discussions about lifestyle activities (Neumark-Sztainer et al., 2010), tailored physical activity advice online (Slootmaker, Chinapaw, Seidell, van Mechelen, \& Schuit, 2010), informing students about strategies to increase their activity at home, e.g. by decreasing television viewing (Singhal, Misra, Shah, \& Gulati, 2010), and online feedback and tailored messages to limit television viewing (Mauriello et al., 2010). Thus to our knowledge, this is one of the first studies to report an evaluation of teacher intervention targeting classroom activity of this age group.

\subsection{Study limitations and strengths}

This study has several strengths: instead of a simplistic single-theory focus, the study combines several social psychological theories and approaches in investigating the processes induced by an intervention tested in an experimental field design. The complex content of the intervention is carefully and transparently reported and mapped onto the assumed theoretical mechanisms (Supplementary file Table 1). Also, operationalizing the active agency and engagement of the intervention participants as their use of behaviour change skills taught to them in the intervention, the scope of this paper goes beyond merely explaining and predicting behaviour with psychological constructs to dynamic change strategies used by individuals. Given the central role of teachers in prevention and health promotion in general, surprisingly little research has been conducted regarding teachers' role in school-based PA interventions, according to a recent systematic review (Lander et al., 2017).

A major strength of this study is the control arm, enabling a comparative exploration of the patterns of change in outcomes and mediators. Considering the similarity of the intervention and control arm teachers' baseline characteristics, the randomization may have been successful and the control group provided an appropriate point of comparison. Yet, a problem is, that in such a pragmatic field-based trial, it was not possible to blind teachers to study arm allocation before the baseline survey.

Despite its strengths, this study has several limitations as well. The relatively small sample size of 123 teachers limits the statistical power of this study and the generalizability of the results. Although the main Let's Move It trial was fully powered to detect changes in student outcomes (Hankonen et al., 2016) and included more than 1100 students, this opportunistic and pragmatic sub-trial of teachers could not have been fully-powered due to practical considerations. It should be noted however that many school- and institution-based cluster-randomized trials include fewer intervention providers than this (Hynynen et al., 2016), which may explain the lack of research in this area (Lander et al., 2017). Lower-than-expected enrolment among teachers (53\% of those approached for participation) also partially explains the low total number of teachers in the sample. Explanations for the low 
participation rate include the busyness of teachers' work in vocational schools and large-scale reforms to the school system which took place at the time of the study. Given the low rate of responses, it is possible that the sample is biased in that, particularly in the control schools, the most eager teachers may have been more likely to respond, with existing highly positive views regarding sitting reduction.

Dropout rates in this study of $38 \%$ and $50 \%$, in the intervention and control groups respectively, must also be mentioned as a limitation. Although we attempted to account for dropout with appropriate multiple imputation procedures, we cannot completely rule out the possibility that differential response rates across groups may have skewed the intervention results. As those who dropped out of the study reported more frequent sitting reduction practices and higher sitting reduction automaticity at baseline, it is possible that those teachers who felt that they were already implementing sitting reduction strategies are missing from the follow-up. On the other hand, considering vocational school teachers' heavy workload and busy working days, it is possible that the teachers who took part in this study are those who are particularly interested in health-related topics, and those not interested did not take part at all.

Due to the novelty of the topic of sitting reduction behaviours and to the rapid pace of the trial development, the measures used for sitting reduction practices have not been formally tested or validated experimentally. Self-report measures of behaviour that are subject to social desirability and memory biases. However, the survey questions were created in collaboration with a multidisciplinary team of experienced researchers, tested for their acceptability and feasibility in the Let's Move It feasibility study (Hankonen et al., 2017) and further refined for the purposes of this study. These measures provided useful data with apparent face validity, but their reliability and validity should be further investigated. Instead of self-report measures, a more reliable approach would have been reports by observers such as students or videomonitoring of activity in classrooms. However, our feasibility study showed a good correspondence between teachers' self-assessment of use of sitting reduction strategies on their students, and students' corresponding report of their teachers' behaviour (Hankonen et al., 2017). As the field is growing, we look forward to research efforts to produce validated self-report measures or digital and automatized, objective observation of classroom activity.

Finally, a remark should be made on the limitations of the current procedure to infer causality. Even if the sample had been sufficiently powered, the relationship between the mediating and dependent variables is necessarily only correlational in a "measurement-of-mediation design" (Pirlott \& MacKinnon, 2016), even though this is not widely acknowledged. This is important to recognize, although "manipulationof-mediation" designs (conducting experimental manipulations targeting the mediator) would be unrealistic and unfeasible in a withintrial pragmatic field study such as this.

In sum, the pragmatic field intervention design inevitably has many methodological limitations. On the other hand, the many undeniable strengths that field experiments have in common, such as studying social psychological phenomena in their natural circumstances, and participant diversity, are likely to increase the veracity and robustness of published research (Maner, 2016), which is currently needed.

\subsection{Constraints on generality}

The current study drew from a population of vocational school teachers in a Nordic country, which may limit its generalizability to other populations of teachers in countries without similar vocational education systems. In addition, all participating teachers had volunteered to take part in a study related to health promotion. The results demonstrated here may therefore not hold among teachers with no interest in promoting active lifestyles or reducing sedentary behaviour among their students. It should be noted that the sample size in this study did not provide sufficient evidence to investigate if the results are likely to be invariant across different types of participants, materials or contexts. However, we have no reason to believe that the results depend on other characteristics of the participants, materials, or context.

\subsection{Implications for research and practice}

An important novel avenue in the research of health behaviour change is our investigation of use of behaviour change techniques - an emerging key theme in the field. The intervention BCT use is a central factor in intervention engagement, and it showed moderate correlation with most social psychological mediators and behaviour. It is clear that creating useful interventions in practice and developing social psychological behaviour change theory, the field should move beyond investigating static psychological states as predictors of behaviour (e.g. perceived behavioural control), and begin investigating what people actually do to change their own behaviour. Future studies may wish to investigate which BCTs were most (or least) frequently taken up by the teachers, or how different combinations of BCTs might be used to reach the target behaviour. This is an example of potential of process evaluations of field experiments, providing important feedback to theory refinement.

While social cognition models have been criticised, especially the predecessor of RAA, the theory of planned behaviour (Sniehotta, Presseau, \& Araujo-Soares, 2014), this work addressed some of the criticism by integrating the more recent RAA into a wider network of theoretical approaches and BCTs. Health behaviour change is a multifaceted, complex issue, and is not fully explained by simplified static models consisting of only a few variables. Therefore, in the future, process models to understand behaviour change may incorporate complex networks of related psychological factors. These may also disentangle interrelationships between determinants, such as potentially differing impact mechanisms of attitudes and habits on behaviour change (Itzchakov, Uziel, \& Wood, 2018).

This study sheds light on the usefulness of various intervention components to teachers. Next, we suggest ways to improve habit-based interventions in this area. Teachers have indicated that their working days can be very chaotic and busy, so they need sitting reduction and behavioural regulation strategies that are easy to use (Laine et al., 2017). It is possible that despite its highlighted importance (e.g. Fleig et al., 2017), the benefits and simplicity of habit formation were not communicated clearly enough in the workshops, which then resulted in low motivation to enact habit formation plans. Habit formation is most easily used with the simplest sitting reduction strategies, e.g. asking students to come pick up materials from the teachers' front desk or starting each lesson by reminding the students that they can stand up and stretch during the lesson as they wish. Use of this kind of simple habit formation strategies does not take time away from teaching or require preparation, and thus it seems fitting to teachers' busy work. However, sitting reduction strategies (options Supplementary file 2) largely differ in their ease of use, and not all of them are suitable for habit formation (e.g., organizing a learning café requires preparation, and thus cannot easily be used whenever one encounters a chosen cue in the classroom). This may not have been communicated in the workshops clearly enough, and thus may have caused misunderstandings making habit formation seem unfeasible.

Broader enactment of the habit formation plans may require clearer guidelines or more intensive support. To make habit formation more appealing to participants, it might be useful to focus only on the simplest sitting reduction strategies and how they can be made habitual. Alternatively, the focus could be placed on planning of sitting reduction, by e.g. asking teachers to create a cue that would remind them about including sitting reduction activities when they plan their lessons. Furthermore, instead of the quite time-consuming tools the Let's Move It intervention had for teachers for making habit formation plans, another option would be to first observe teachers' classroom practices to identify possible triggers, and then attaching prompts to these triggers. 
Finally, other ways of delivery than workshops could be considered, e.g. a brief theory-based manual to reducing students' sitting, including practical strategies and simple habit formation advice. Previously Lally, Chipperfield, and Wardle (2008) have shown that in the context of weight loss, habit formation can be successfully prompted by a simple leaflet. Another delivery option to reach more teachers is creating online-workshops or videos.

\subsection{Health in context}

This paper advances the study of context in social health psychology in several ways. The Let's Move It intervention was based on a careful analysis of the social, physical and curricular context (e.g. key informant interviews, formative research, collaborative planning) in Finnish schools. The interventions were conducted on multiple levels, hence not just targeting individuals but also their interaction (social context) and the physical environment (physical context). Taking the context into account at all stages was thus one key element of the study. This enables one key advance: ecological validity and impact.

After a long period of studying social health psychological issues and theories in cross-sectional, or observational longitudinal designs or in the laboratory, testing theories in 'real world' contexts will advance our understanding of the phenomena (Rothman, 2004), exemplify a solution-oriented social science (Watts, 2017), and in doing so, demonstrate the societal impact of social science. We hope to have done all of these. Secondly, context is also visible in that the behaviour we studied is actually a social behaviour, and students received an intervention specifically directed to themselves, as opposed to lab studies which might use vicarious learning to capture the social behaviours of others. Furthermore, actual control was altered (through the multi-level intervention increasing opportunity) before perceived control was addressed. In sum, taking the interpersonal and physical context into account in these ways is a strength of our approach, and such interventions may be more conducive to creating sustainable behaviour change.

As a future direction, the study of context in social health psychology may benefit from drawing from complexity approaches (Hawe, 2015). Simple interventions are most times unlikely to change behavioural patterns related to health and well-being, and more complex interventions, including several system levels, will be needed. However, despite many instances of complex systems approaches present also in the current intervention, truly embracing complexity goes beyond what was done in this study. Complexity, as a property of the intervention and the context into which it is placed, poses challenges to not only intervention design but also evaluation, as nonlinear relationships and transitions can be expected. Study of such systems requires readiness to understand self-organization and emergence as well as context-specific effects (Rogers, 2008), which were not taken into account here. However, this may be a fruitful avenue to pursue in the future (Sniehotta et al., 2017). Furthermore, mechanisms of behaviour change may not be uniform for all individuals, and an attempt to study these on a grouplevel may conceal important inter-individually varying dynamics (Rogers, 2008; Hawe, 2015; Fisher, Medaglia, \& Jeronimus, in press), and we recommend future research to take this into account.

\section{Conclusion}

Teachers often control classroom environments, and therefore, in school settings, they can have considerable influence over the extent to which students are active or sedentary. The teacher training intervention tested here was developed as part of the Let's Move It intervention, and utilized psychological theories and research on habit formation to help teachers form automatic routines related to reducing sedentary behaviour in their classrooms. The teacher training intervention led to increases in several behavioural determinants from the reasoned action approach, and had small effects on teachers' self-reported use of strategies to reduce total sitting time in their classrooms in this exploratory evaluation. Furthermore, a theory-based process evaluation indicated that this increased use of strategies to reduce total sitting time was mediated by perceived behavioural control after the intervention. These findings indicate that a teacher training intervention which includes habit formation strategies can increase teachers' intentions and efforts to reduce sedentary behaviour in the classroom. If rolled out on a broad scale, such teacher-led interventions could help to increase physical activity and reduce sedentary behaviour among students in vocational schools. This study demonstrates how investigations of intervention outcomes can be complemented by theory-based process evaluation even in complex interventions evaluated in the field setting.

Supplementary data to this article can be found online at https:// doi.org/10.1016/j.jesp.2018.08.004.

\section{Acknowledgements}

\section{Funding}

Ministry of Education and Culture, Finland (grant number OKM/81/ 626/2014) and Academy of Finland (grant number 285283).

\section{References}

Araújo-Soares, V., Hankonen, N., Presseau, J., Rodrigues, A., \& Sniehotta, F. F. (2018). Developing behaviour change interventions for self-management in chronic illness: An integrative overview. European Psychologist. https://doi.org/10.1027/1016-9040/ a000330 (epub ahead of print).

Bellg, A. J., Borrelli, B., Resnick, B., Hecht, J., Minicucci, D. S., Ory, M., ... Czajkowski, S. (2004). Enhancing treatment fidelity in health behavior change studies: Best practices and recommendations from the NIH Behavior Change Consortium. Health Psychology, 23(5), 443-451. https://doi.org/10.1037/0278-6133.23.5.443.

Biddle, S. J., Pearson, N., Ross, G. M., \& Braithwaite, R. (2010). Tracking of sedentary behaviours of young people: A systematic review. Preventive Medicine, 51(5), 345-351. https://doi.org/10.1016/j.ypmed.2010.07.018.

Carson, V., Hunter, S., Kuzik, N., Gray, C. E., Poitras, V. J., Chaput, J. P., ... Tremblay, M. S. (2016). Systematic review of sedentary behaviour and health indicators in schoolaged children and youth: An update. Applied Physiology, Nutrition, and Metabolism, 41(6 Suppl. 3), S240-S265. https://doi.org/10.1139/apnm-2015-0630.

Fishbein, M., \& Ajzen, I. (2010). Predicting and changing behavior: The reasoned action approach. New York, NY [etc.]: Psychology Press.

Fisher, A. J., Medaglia, J. D., \& Jeronimus, B. F. (2018). Lack of group-to-individual generalizability is a threat to human subjects research. Proceedings of the National Academy of Sciences. https://doi.org/10.1073/pnas.1711978115 201711978.

Fleig, L., Gardner, B., Keller, J., Lippke, S., Pomp, S., \& Wiedemann, A. U. (2017). What contributes to action plan enactment? Examining characteristics of physical activity plans. British Journal of Health Psychology, 22(4), 940-957. https://doi.org/10.1111/ bjhp. 12263.

Fleig, L., McAllister, M. M., Chen, P., Iverson, J., Milne, K., McKay, H. A., ... Ashe, M. C. (2016). Health behaviour change theory meets falls prevention: Feasibility of a habitbased balance and strength exercise intervention for older adults. Psychology of Sport and Exercise, 22, 114-122. https://doi.org/10.1016/j.psychsport.2015.07.002.

Francis, J. J., Eccles, M. P., Johnston, M., Walker, A., Grimshaw, J., Foy, R., ... Bonetti, D. (2004). Constructing questionnaires based on the theory of planned behaviour. University of Newcastle.

Gardner, B. (2015). A review and analysis of the use of 'habit' in understanding, predicting and influencing health-related behaviour. Health Psychology Review, 9(3), 277-295. https://doi.org/10.1080/17437199.2013.876238.

Gardner, B., Abraham, C., Lally, P., \& de Bruijn, G.-J. (2012). 'The habitual use of the Selfreport Habit Index': A reply. Annals of Behavioral Medicine, 43. https://doi.org/10. 1007/s12160-011-9317-6.

Gardner, B., Sheals, K., Wardle, J., \& McGowan, L. (2014). Putting habit into practice, and practice into habit: A process evaluation and exploration of the acceptability of a habit-based dietary behaviour change intervention. International Journal of Behavioral Nutrition and Physical Activity, 11, 135. https://doi.org/10.1186/s12966-014-0135-7.

Greaves, C. J. (2015). Uptake of behavior change techniques - A key focus for process analysis and for intervention delivery: A comment on Hankonen et al. Annals of Behavioral Medicine, 49(1), 1-2. https://doi.org/10.1007/s12160-014-9630-y.

Hankonen, N., Absetz, P., Haukkala, A., \& Uutela, A. (2009). Socioeconomic status and psychosocial mechanisms of lifestyle change in a type 2 diabetes prevention trial. Annals of Behavioral Medicine, 38(2), 160. https://doi.org/10.1007/s12160-0099144-1.

Hankonen, N., Heino, M. T., Araujo-Soares, V., Sniehotta, F. F., Sund, R., Vasankari, T., ... Haukkala, A. (2016). 'Let's move It' - a school-based multilevel intervention to increase physical activity and reduce sedentary behaviour among older adolescents in vocational secondary schools: A study protocol for a cluster-randomised trial. BMC Public Health, 16, 451. https://doi.org/10.1186/s12889-016-3094-x.

Hankonen, N., Heino, M. T. J., Hynynen, S.-T., Laine, H., Araújo-Soares, V., Sniehotta, F. 
F., ... Haukkala, A. (2017). Randomised controlled feasibility study of a school-based multi-level intervention to increase physical activity and decrease sedentary behaviour among vocational school students. International Journal of Behavioral Nutrition and Physical Activity, 14(1), 37. https://doi.org/10.1186/s12966-017-0484-0.

Hankonen, N., Sutton, S., Prevost, A. T., Simmons, R. K., Griffin, S. J., Kinmonth, A. L., \& Hardeman, W. (2015). Which behavior change techniques are associated with changes in physical activity, diet and body mass index in people with recently diagnosed diabetes? Annals of Behavioral Medicine, 49(1), 7-17. https://doi.org/10. 1007/s12160-014-9624-9.

Hawe, P. (2015). Lessons from complex interventions to improve health. Annual Review of Public Health, 36, 307-323. https://doi.org/10.1146/annurev-publhealth-031912114421.

Hayes, A. F. (2013). Introduction to mediation, moderation, and conditional process analysis: A regression-based approach. Guilford Publications.

Hynynen, S. T., van Stralen, M. M., Sniehotta, F. F., Araújo-Soares, V., Hardeman, W., Chinapaw, M. J. M., ... Hankonen, N. (2016). A systematic review of school-based interventions targeting physical activity and sedentary behaviour among older adolescents. International Review of Sport and Exercise Psychology, 9(1), 22-44. https:// doi.org/10.1080/1750984X.2015.1081706.

IBM Corporation (2012). SPSS: Missing Values 21. Armonk, NY: IBM Corporation Retrieved from: http://www.sussex.ac.uk/its/pdfs/SPSS_Missing_Values_21.pdf.

Itzchakov, G., Uziel, L., \& Wood, W. (2018). When attitudes and habits don't correspond: Self-control depletion increases persuasion but not behavior. Journal of Experimental Social Psychology, 75(Supplement C), 1-10. https://doi.org/10.1016/j.jesp.2017.10. 011

JaKa, M. M., Haapala, J. L., Trapl, E. S., Kunin-Batson, A. S., Olson-Bullis, B. A., Heerman, W. J., ... Sherwood, N. E. (2016). Reporting of treatment fidelity in behavioural paediatric obesity intervention trials: A systematic review. Obesity Reviews, 17(12), 1287-1300. https://doi.org/10.1111/obr.12464.

Knittle, K., De Gucht, V., Hurkmans, E., Vlieland, T. V., \& Maes, S. (2016). Explaining physical activity maintenance after a theory-based intervention among patients with rheumatoid arthritis: Process evaluation of a randomized controlled trial. Arthritis Care \& Research, 68(2), 203-210. https://doi.org/10.1002/acr.22647.

Koster, A., Caserotti, P., Patel, K. V., Matthews, C. E., Berrigan, D., Van Domelen, D. R., ... Harris, T. B. (2012). Association of sedentary time with mortality independent of moderate to vigorous physical activity. PLoS One, 7(6), e37696. https://doi.org/10 1371/journal.pone.0037696.

Laine, H., Araújo-Soares, V., Haukkala, A., \& Hankonen, N. (2017). Acceptability of strategies to reduce student sitting. Health Promotion Practice, 18(1), 44-53. https:// doi.org/10.1177/1524839916677209.

Lally, P., Chipperfield, A., \& Wardle, J. (2008). Healthy habits: Efficacy of simple advice on weight control based on a habit-formation model. International Journal of Obesity, 32. https://doi.org/10.1038/sj.ijo.0803771.

Lally, P., \& Gardner, B. (2013). Promoting habit formation. Health Psychology Review, 7(Suppl. 1), S137-S158. https://doi.org/10.1080/17437199.2011.603640.

Lally, P., van Jaarsveld, C. H. M., Potts, H. W. W., \& Wardle, J. (2010). How are habits formed: Modelling habit formation in the real world. European Journal of Social Psychology, 40. https://doi.org/10.1002/ejsp.674.

Lander, N., Eather, N., Morgan, P. J., Salmon, J., \& Barnett, L. M. (2017). Characteristics of teacher training in school-based physical education interventions to improve fundamental movement skills and/or physical activity: A systematic review. Sports Medicine, 47(1), 135-161. https://doi.org/10.1007/s40279-016-0561-6.

Maner, J. K. (2016). Into the wild: Field research can increase both replicability and realworld impact. Journal of Experimental Social Psychology, 66(Supplement C), 100-106. https://doi.org/10.1016/j.jesp.2015.09.018.

Mauriello, L. M., Ciavatta, M. M., Paiva, A. L., Sherman, K. J., Castle, P. H., Johnson, J. L., \& Prochaska, J. M. (2010). Results of a multi-media multiple behavior obesity prevention program for adolescents. Preventive Medicine, 51(6), 451-456. https://doi. org/10.1016/j.ypmed.2010.08.004

McEachan, R., Taylor, N., Harrison, R., Lawton, R., Gardner, P., \& Conner, M. (2016). Meta-analysis of the reasoned action approach (RAA) to understanding health behaviors. Annals of Behavioral Medicine, 50, 592-612. https://doi.org/10.1007/ s12160-016-9798-4.

Michie, S., Richardson, M., Johnston, M., Abraham, C., Francis, J., \& Hardeman, W. (2013). The behavior change technique taxonomy (v1) of 93 hierarchically clustered techniques: Building an international consensus for the reporting of behavior change interventions. Annals of Behavioral Medicine, 46. https://doi.org/10.1007/s12160013-9486-6.

Moore, G., Audrey, S., Barker, M., Bond, L., Bonell, C., Hardeman, W., ... Baird, J. (2015). Process evaluation of complex interventions: Medical Research Council guidance. British Medical Journal, 350. https://doi.org/10.1136/bmj.h1258 h1258.

Morton, K. L., Atkin, A. J., Corder, K., Suhrcke, M., \& van Sluijs, E. M. F. (2016). The school environment and adolescent physical activity and sedentary behaviour: A mixed-studies systematic review. Obesity Reviews, 17(2), 142-158. https://doi.org/ 10.1111/obr.12352.

Naylor, P. J., Nettlefold, L., Race, D., Hoy, C., Ashe, M. C., Wharf Higgins, J., \& McKay, H. A. (2015). Implementation of school based physical activity interventions: A systematic review. Preventive Medicine, 72, 95-115. https://doi.org/10.1016/j.ypmed. 2014.12.034.

Neumark-Sztainer, D. R., Friend, S. E., Flattum, C. F., Hannan, P. J., Story, M. T., Bauer, K. W., ... Petrich, C. A. (2010). New moves-preventing weight-related problems in adolescent girls a group-randomized study. American Journal of Preventive Medicine, 39(5), 421-432. https://doi.org/10.1016/j.amepre.2010.07.017.

Owen, N., Sparling, P. B., Healy, G. N., Dunstan, D. W., \& Matthews, C. E. (2010). Sedentary behavior: Emerging evidence for a new health risk. Mayo Clinic Proceedings, 85(12), 1138-1141. https://doi.org/10.4065/mcp.2010.0444.

Peters, L. W. H., Kok, G., Ten Dam, G. T. M., Buijs, G. J., \& Paulussen, T. G. W. M. (2009) Effective elements of school health promotion across behavioral domains: A systematic review of reviews. BMC Public Health, 9, 182. https://doi.org/10.1186/1471 2458-9-182.

Pirlott, A. G., \& MacKinnon, D. P. (2016). Design approaches to experimental mediation. Journal of Experimental Social Psychology, 66(Supplement C), 29-38. https://doi.org/ 10.1016/j.jesp.2015.09.012.

Rezende, L. F. M.d., Rey-López, J. P., Matsudo, V. K. R., \& Luiz, O.d. C. (2014). Sedentary behavior and health outcomes among older adults: A systematic review. BMC Public Health, 14(1), 333. https://doi.org/10.1186/1471-2458-14-333.

Rogers, P. J. (2008). Using programme theory to evaluate complicated and complex aspects of interventions. Evaluation, 14(1), 29-48. https://doi.org/10.1177 1356389007084674.

Rothman, A. J. (2004). "Is there nothing more practical than a good theory?": Why innovations and advances in health behavior change will arise if interventions are used to test and refine theory. International Journal of Behavioral Nutrition and Physical Activity, 1(1), https://doi.org/10.1186/1479-5868-1-11.

Sheeran, P., Maki, A., Montanaro, E., Avishai-Yitshak, A., Bryan, A., Klein, W. M., ... Rothman, A. J. (2016). The impact of changing attitudes, norms, and self-efficacy on health-related intentions and behavior: A meta-analysis. Health Psychology, 35(11), 1178-1188. https://doi.org/10.1037/hea0000387.

Singhal, N., Misra, A., Shah, P., \& Gulati, S. (2010). Effects of controlled school-based multi-component model of nutrition and lifestyle interventions on behavior modification, anthropometry and metabolic risk profile of urban Asian Indian adolescents in North India. European Journal of Clinical Nutrition, 64(4), 364-373. https://doi. org/10.1038/ejen.2009.150.

Slootmaker, S. M., Chinapaw, M. J., Seidell, J. C., van Mechelen, W., \& Schuit, A. J. (2010). Accelerometers and Internet for physical activity promotion in youth? Feasibility and effectiveness of a minimal intervention [ISRCTN93896459]. Preventive Medicine, 51(1), 31-36. https://doi.org/10.1016/j.ypmed.2010.03.015.

Sniehotta, F. F., Araújo-Soares, V., Brown, J., Kelly, M. P., Michie, S., \& West, R. (2017) Complex systems and individual-level approaches to population health: A false dichotomy? The Lancet Public Health, 2(9), e396-e397. https://doi.org/10.1016/S2468 2667(17)30167-6.

Sniehotta, F. F., Presseau, J., \& Araujo-Soares, V. (2014). Time to retire the theory of planned behaviour. Health Psychology Review, 8(1), 1-7. https://doi.org/10.1080/ 17437199.2013 .869710$.

Thorp, A. A., Owen, N., Neuhaus, M., \& Dustan, D. W. (2011). Sedentary behaviors and subsequent health outcomes in adults a systematic review of longitudinal studies, 1996-2011. American Journal of Preventive Medicine, 41. https://doi.org/10.1016/j. amepre.2011.05.004.

Watts, D. J. (2017). Should social science be more solution-oriented? Nature Human Behaviour, 1. https://doi.org/10.1038/s41562-016-0015. 